\title{
Vehicles Emissions Under Different Driving Conditions in Urban Areas
}

\author{
GELU COMAN ${ }^{1}$, MUGUREL SALVADORE BURCIU ${ }^{1}$, NICUSOR BAROIU²* \\ 'Dunarea de Jos University, Thermal Systems and Environmental Engineering Department, 47 Domneasca Str., 800008, Galati, \\ Romania \\ 2Dunarea de J os University, Manufacturing Engineering Department, 47 Domneasca Str., 800008, Galati, Romania
}

\begin{abstract}
The road traffic is one of the main sources of atmospheric pollution in urban areas. This study aims to identify the emissions level for different driving regimes of diesel-powered vehicles that run into urban areas. The study has been performed in laboratory conditions and simulates various driving modes. This paper investigates the effects of vehicle speed, fuel consumption, acceleration, vehicle load on gaseous pollutant emissions $\left(\mathrm{NO}_{x^{\prime}} \mathrm{CO}_{2}, \mathrm{CO}\right)$. The different pollution levels with smoke are also analyzed between idling regimes (maximum opacity index for fast acceleration between minimum and maximum speed) and different loads. The paper states some recommendations concerning the optimal operating regimes of the cars in urban areas, based on the conclusions on the measured levels of pollution.
\end{abstract}

Keywords: atmospheric pollution, diesel engine, gaseous emissions, smoke emission, urban areas

Air pollution is a serious environmental problem in most urban areas. The main legislative instrument to achieve the 2030 objectives of the Clean Air Programme is the Directive 2016/2284/EU on the reduction of national emissions of certain atmospheric pollutants which entered into force on 31 December 2016 [1]. Air pollution is an important public health problem in most of the cities [2, 3].

Without effective measures to mitigate the adverse impacts of motor vehicle use, the living environment in the cities will continue to deteriorate and become increasingly unbearable [4-6]. Road traffic is considered to be one of the main sources of particulate matter and polycyclic aromatic hydrocarbon pollution in urban areas [7].

According to ACEA (European Automobile Manufacturers Association), overall in $2016,49.5 \%$ of all new passenger cars registered in Western Europe ran on diesel and $45.8 \%$ on petrol, while in Romania, $37.4 \%, 61.9 \%$ and $0.7 \%$ of this cars ran on diesel, petrol and alternative fuels, respectively [8]. According to the same Association, out of the total cars running in Romania, 32\% are over 10 years old.

The new Romanian legislation on pollution standards for second-hand cars has as a consequence the import of more than 500.000 used cars in 2017 [9]. The increasing number of passenger automotives with diesel engines and the intensive traffic in urban areas have a negative effect on both environment and human health $[10,11]$,. Chana et al. [12] describes in his study the emissions from actual operations and their dependence on the speed or age of the vehicle.

One of the most important family of traffic-related pollutants is represented by nitrogen oxides $\left(\mathrm{NO}_{\mathrm{x}}\right)$, whose main contributors to their emissions in Europe are the mobile sources (38.4\%) [13]. In order to limit the pollutants emissions level at diesel engines, especially $\mathrm{NO}_{x}$ and soot, the pollution legislations become more severe, this fact leading to the applying of new active methods for fuels combustion control, and using alternative fuel too $[14,15]$.

The present paper aims to show precisely the difference between the $\mathrm{NO}_{x}, \mathrm{CO}_{2} \mathrm{CO}$ emissions and smoke index values determined at idling speed by free acceleration from minimum speed to maximum idle speed and the one determined at the load regimes specific to the normal operating conditions, in case of a diesel direct injection engine. The paper discusses, based on the experimental data, the effect of speed operating modes up to 4000 [rpm] and the running vehicle speed between 40 and $80 \mathrm{~km} / \mathrm{h}$ on the amount of $\mathrm{NO}_{x^{\prime}} \mathrm{CO}, \mathrm{CO}_{2}$ and smoke emissions.

\section{Experimental part}

The equipment used for experimental determinations includes a vehicle equip with diesel engine, diagnostic equipment and an analyzer of exhaust gases. The vehicle used in the study, has the characteristics indicated in the table 1.

Table 1

VEHICLE CHARACTERISTICS

\begin{tabular}{|l|c|}
\hline Maximum power (HP) & 63 \\
\hline Maximum rotation of engine (rpm) & 4500 \\
\hline Engine volume $\left(\mathrm{cm}^{3}\right)$ & 1870 \\
\hline Cylinders number & 4 \\
\hline Type of fuel and fuel system & Standard diesel injection-SDI \\
\hline Environmental standard & EURO III \\
\hline Maximum authorized weight (kg) & 1460 \\
\hline
\end{tabular}

The roller stand enables the dynamical determination of the engine's power and torque, as well as of the power and torque of the vehicle's engine wheels. The V-TechDyno VT-2 / B1 Chassis dynamometer has been used (fig. 1).

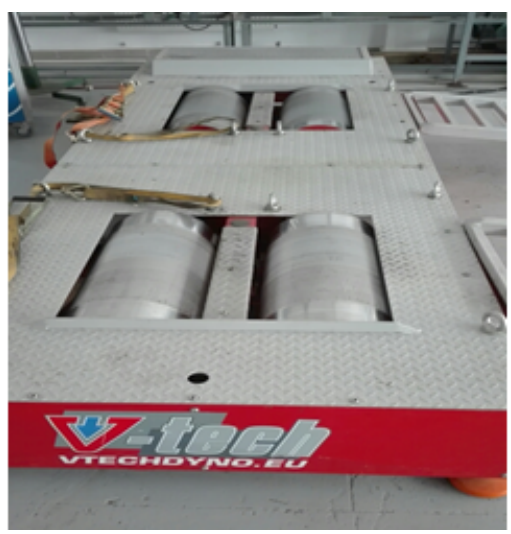

Fig. 1 The V-TechDyno VT-2 / B1 Chassis dynamometer

\footnotetext{
* email: Nicusor.Baroiu@ugal.ro; Phone: 0721771000
} 
The equipment used to diagnose the car and take over the operating parameters is of type Autocom CARS CDP+. The gas analyzer is Johnson Controls - Ultima 600 type, 800-65 model, produced by J ohnson Controls Automotive Electronics (fig. 2).

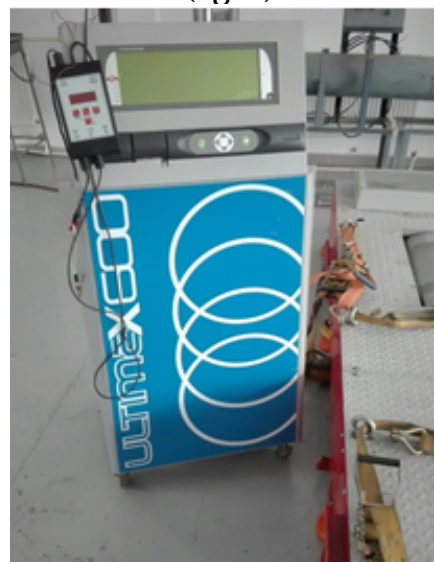

Fig. 2 The Johnson Controls Ultima 600 gas analyzer

To perform the load tests, the constant speed method (RPM) was used. Constant RPM mode allows maintaining the desired rpm rate by applying additional load with eddy currentbrakes. Due to the increasing resistance introduced by the electric brake as the acceleration increases, the engine speed is kept constant at the desired value.

Using the mentioned above equipments, experimental determinations were carried out for opacity coefficient at low loads, respectively high loads regimes. At the same time, variations in engine speed, accelerator pedal position, fuel flow (expressed in $\mathrm{mm}^{3} /$ stroke) and running speed were taken over. For urban driving regime, the vehicle running speed was considered between 40 and $80 \mathrm{~km} / \mathrm{h}$. Load determinations were performed, considering the variation of the accelerator pedal position between 25 $100 \%$ and the constant speed method for engine speeds between 1500-4000 rpm.

\section{Results and discussions}

In table 2 are presented the engine load, engine speed and pollutant emissions at different vehicle speed. One can notice a significant variation of gaseous pollutant emissions with the vehicle running speed.

Figure 3 shows the $\mathrm{NO}_{x^{\prime}} \mathrm{CO}$ emissions and exhaust gas temperature depending on vehicle speed

Concerning the effect of vehicle speed and exhaust gas temperature on $\mathrm{NO}_{\mathrm{x}}$ and $\mathrm{CO}$ emissions, it can be noted that for running speeds smaller than $60 \mathrm{~km} / \mathrm{h}$, the NO emissions are reduced while the $\mathrm{CO}$ emissions are increased. For driving speeds exceeding $60 \mathrm{~km} / \mathrm{h}$, the engine load and the exhaust gas temperature increase favoring the $\mathrm{NO}_{x}$ emissions.

The $\mathrm{CO}_{2}, \mathrm{O}_{2}$ emissions and real air ratio (ë) depending on vehicle speed are presented in figure 4.

For running speeds above $60 \mathrm{~km} / \mathrm{h}$, it is noticed that the $\mathrm{CO}_{2}$ emissions are reduced compared to those recorded at lower speeds. The reduction of $\mathrm{CO}_{\text {}}$ at high vehicle speed is explained by the increasing amount of $\mathrm{O}_{2}$ into the combustion chamber and improving combustion efficiency.

The evolution of the measured values of the smoke index, for regimes of average and high loads, is shown in figure 5 .

Table 2

THE VEHICLE SPEED, ENGINE LOAD, ENGINE SPEED AND POLLUTANT EMISSIONS

\begin{tabular}{|c|c|c|c|c|c|c|c|}
\hline $\begin{array}{c}\text { Vehicle speed } \\
{[\mathrm{km} / \mathbf{h}]}\end{array}$ & $\begin{array}{c}\text { Engine } \\
\text { speed } \\
{[\mathrm{rpm}]}\end{array}$ & $\begin{array}{c}\text { Engine } \\
\text { load } \\
{[\%]}\end{array}$ & $\begin{array}{c}\text { NOx } \\
{[\mathrm{ppm}]}\end{array}$ & $\begin{array}{c}\text { NO } \\
{[\mathrm{ppm}]}\end{array}$ & $\begin{array}{c}\mathrm{CO} \\
{[\mathrm{ppm}]}\end{array}$ & $\begin{array}{c}\mathrm{CO}_{2} \\
{[\%]}\end{array}$ & $\begin{array}{c}\mathrm{O}_{2} \\
{[\%]}\end{array}$ \\
\hline 40 & 1500 & 14 & 65 & 63 & 403 & 7.6 & 10.6 \\
\hline 50 & 1740 & 21 & 68 & 66 & 481 & 6.9 & 11.5 \\
\hline 60 & 2055 & 26 & 70 & 68 & 458 & 8.2 & 9.8 \\
\hline 70 & 2390 & 29 & 108 & 105 & 28 & 6.9 & 11.5 \\
\hline 80 & 2745 & 31 & 211 & 205 & 27 & 3.9 & 15.6 \\
\hline
\end{tabular}

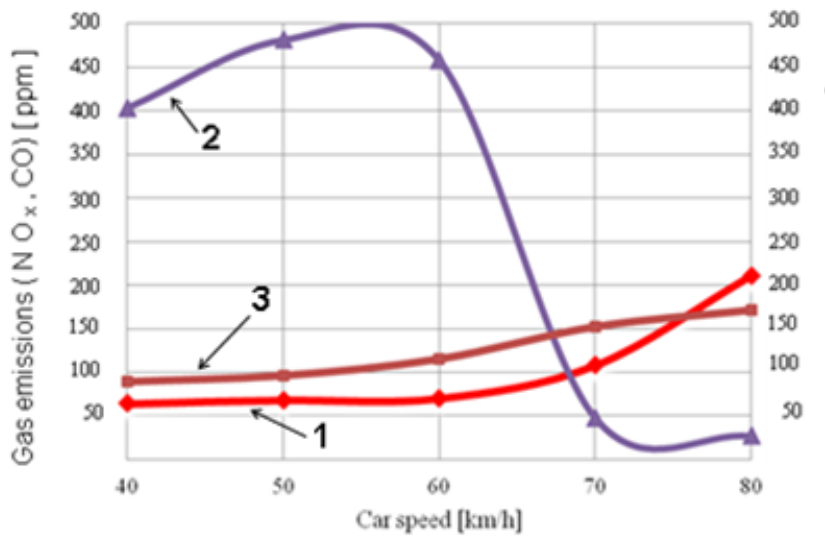

$1 \rightarrow \mathrm{NOx}[\mathrm{ppm} \mid \mathbf{2} \rightarrow \mathrm{CO}[\mathrm{ppm} \mid \mathbf{3}-\mathrm{T}$ gases $[\mathrm{C}]$

Fig. 3. Gas emissions ( $\left.\mathrm{NO}_{x^{\prime}} \mathrm{CO}\right)$ and exhaust gas temperature depending on vehicle speed

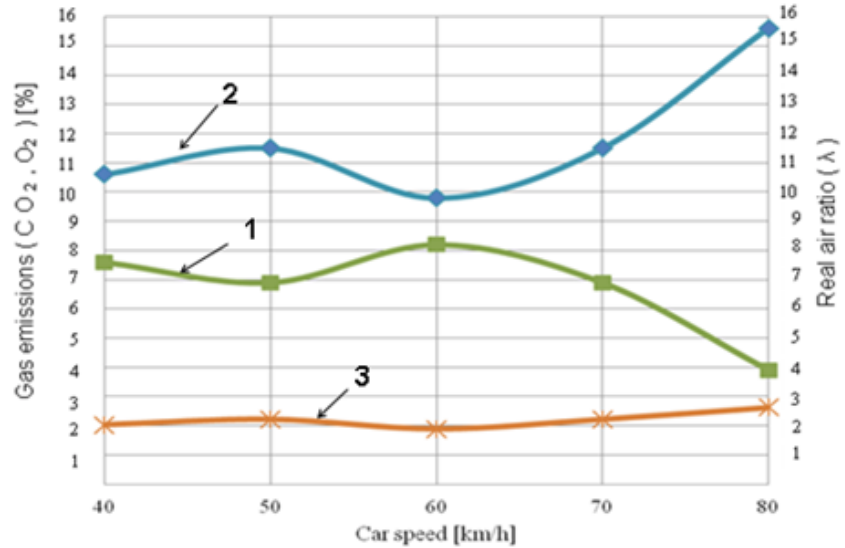

$1=-\mathrm{CO} 2[\%] 2 \rightarrow \mathrm{O} 2[\%] 3-$ Real air ratio

Fig. 4. Gas emissions $\left(\mathrm{CO}_{2}, \mathrm{O}_{2}\right)$ and real air ratio depending on vehicle speed 

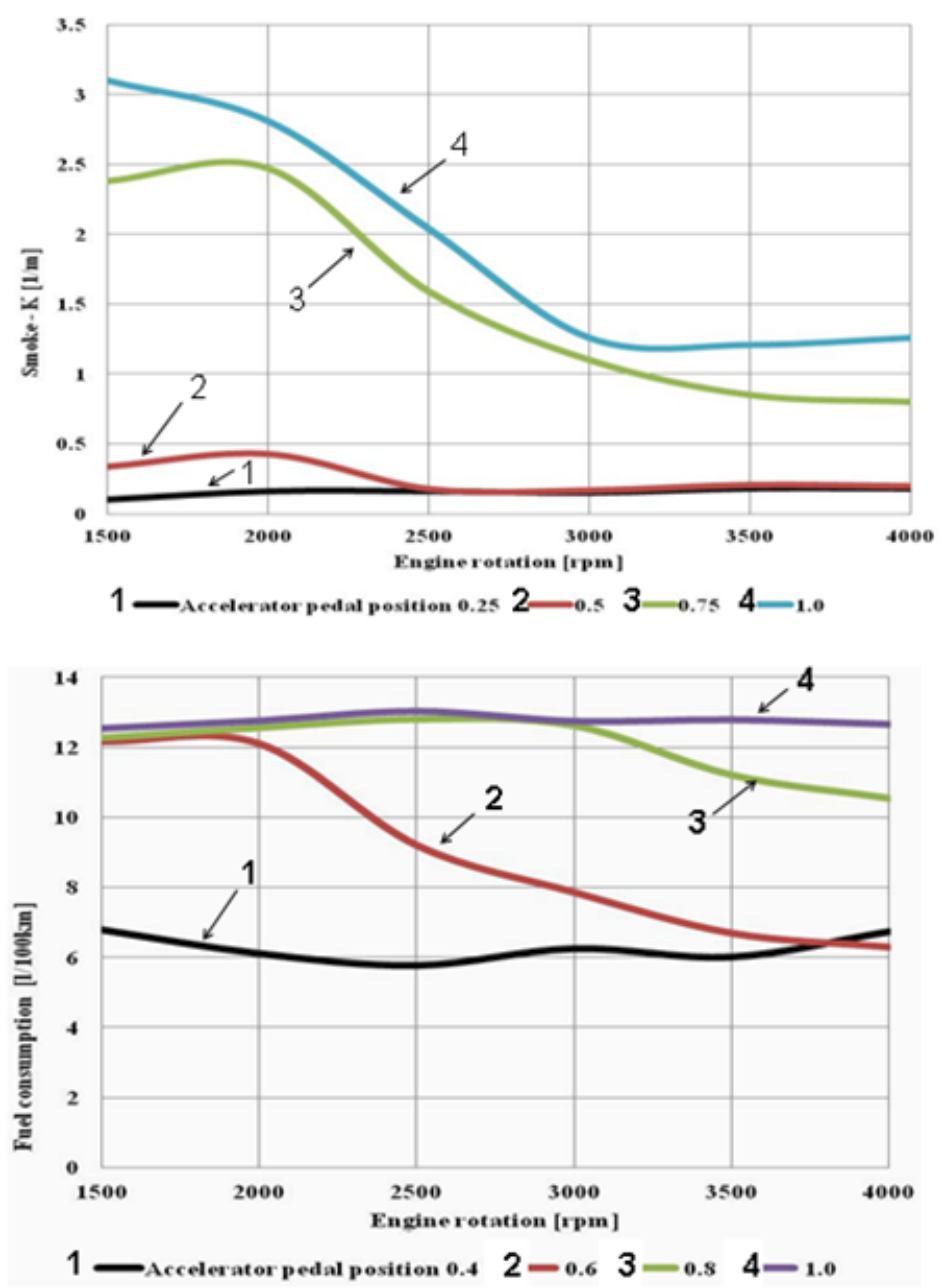

Following the evolution of the smoke index values presented in figure 5, for various speeds and loads, the following observations can be highlighted:

- values of smoke index $k \geq 2.5 \mathrm{~m}^{-1}$ have been measured for speeds smaller or equal than $2000 \mathrm{rpm}$ and high loads corresponding to the acceleration positions larger or equal than 0.75 , which means exceeds the level of smoke measured in the dynamic idle regime as well as the smoke limit level specified in the anti-pollution legislation (for a car equipped with a not supercharged diesel engine with standard diesel injection, the smoke index $\mathrm{k} \leq 2.5 \mathrm{~m}^{-1}$ );

- for engine speeds exceeding $2500 \mathrm{rpm}$ and for average and high loads, the values of smoke index $k$ decrease below $2 \mathrm{~m}^{-1}$; the reduction of smoke at high speeds and at medium and high loads is explained by the favorable influence of the turbulence increase on the rate of combustion of the fuel mixture as well as on the greater amount of air introduced into the combustion chamber when the speed increases.

Figure 6 shows an increase of at least 2 times the fuel consumption, between operating modes with low speed and low and medium loads respectively operating modes with high load and rotations.

Concerning the effect of operating modes and engine loads on fuel consumption, it can be noted that at lower speeds and high loads (such as maximum torque regimes), the smoke level increases, surpassing the level of smoke measured in the idle mode as well as smoke levels indicated in the anti-pollution legislation (for a car equipped with a not supercharged diesel engine with standard diesel injection, the smoke index $\mathrm{k} \leq 2.5 \mathrm{~m}^{-1}$ ). For lower speeds regimes and high loads (such as maximum torque regimes), the smoke level increases, surpassing the level of smoke measured in the idle mode as well as smoke
Fig. 5. Smoke at different rotation of engine and accelerator pedal positions

Fig. 6. Fuel consumption measured in [1/100km] depends of accelerator pedal position and rotation in load regimes levels indicated in the anti-pollution legislation. On the other hand, for high load conditions it is advisable that the engine run at speeds above $2500 \mathrm{rpm}$, as in this case the level of smoke will drop. According to these determinations and the variation of the smoke index, for positions of acceleration disposed between $75 \div 100 \%$ and speeds between $2500 \div 4000 \mathrm{rpm}$, the smoke index reached values of $0.8 \div 2 \mathrm{~m}^{-1}$.

\section{Conclusions}

Our studies on the influence of urban driving regime on the $\mathrm{NO}_{x}, \mathrm{CO}_{2}, \mathrm{CO}$ and smoke emissions led to several significant conclusions.

The amount of $\mathrm{NO}_{x}$ emissions increases with the vehicle running speed and engine load. It is advisable that the running speed in urban regime not exceed to $60 \mathrm{~km} / \mathrm{h}$.

The $\mathrm{CO}$ and $\mathrm{CO}_{2}$ emissions decrease for running speed above $60 \mathrm{~km} / \mathrm{h}$, while the exhaust gas temperature increases favoring the $\mathrm{NO}_{\mathrm{x}}$ emissions.

To reduce the smoke, $\mathrm{CO}$ and $\mathrm{CO}_{2}$ pollutants it is recommended to avoid operating at engine speed modes below 2500 [rpm] and acceleration positions over $70 \%$.

According to the determinations made, for engine speeds of $1500 \div 2000$ [rpm], the smoke index reached values of $2.5 \div 3.1 \mathrm{~m}^{-1}$. For high load conditions it is advisable that the engine run at speeds above $2500 \mathrm{rpm}$, as in this case the level of $\mathrm{CO}_{2}, \mathrm{CO}$ and smoke will drop.

The smoke level measured in the dynamic mode between idle and maximum speed does not exceed the permissible limit $\mathrm{k}<2.5 \mathrm{~m}^{-1}$, the measured value being $\mathrm{k}$ $=1.86 \mathrm{~m}^{-1}$.

Besides adopting a responsible driving mode, the main measures to reduce pollutant emissions are maintaining restrictions for heavy traffic in urban areas and reducing traffic congestion. 


\section{References}

1.***European Union, Directive 2016/2284/EC of the European Parliament and of the Council of 14 December 2016 on the reduction of national emissions of certain atmospheric pollutants, amending Directive 2003/35/EC and repealing Directive 2001/81/EC, Brussels. 2. LUCA, F.A., IOAN, C.A., Environmental Engineering and Management Journal, 11, 2012, p. 377.

3. BONTOS, M.D., VASILIU, D., Rev. Chim. (Bucharest), 67, no. 9, 2016, p. 1854.

4. TCHEPEL, O., BORREGO, C., J ournal of Environmental Monitoring, 12, 2010, p. 544.

5. PATRONAS, D., KARIDA A., PAPADOPOULOU, A., PISIHA, A., XIPOLITOS, K., KOKKINIS, G., VOSNAIKOS, K., GRAMMATIKIS, B., VOSNIAKOS, F., VASDEKIS, K., J ournal of Environmental Protection and Ecology, 2, 2009, p. 332.

6. POPESCU, F., IONEL I., UNGUREANU, C., J ournal of Environmental Protection and Ecology, 10, 2009, p. 1.

7. BUCUR, E., DANET, A.F., Rev. Chim. (Bucharest), 67, no. 4, 2016, p. 621.
8. *** European Automobile Manufacturers' Association, http:// www.acea.be/

9. *** Roumanian Automobile Manufacturers' Association, http:// www.acarom.ro/

10. VINCZE-CSOM, V., DOMOKOS, E., BUI, P., NAGY, G., REDEY, A., Environmental Engineering and Management J ournal, 11, 2012, p. 2083.

11. PETROVIC V.S., Thermal Science, 12, no. 2, 2008, p. 183.

12. CHANA, T.L.,NING, Z.,CHEUNG, C.S., HUNG, W.T., DONG, G., Atmospheric Environment, 38, 2004, p. 2055.

13. SCHIAVON, M., ANTONACCI, G., RADA, E.C., RAGAZZI, M., ZARDI, D., Rev. Chim. (Bucharest), 65, no. 1, 2014, p. 61.

14. CERNAT, A., PANA, C., NEGURESCU, N., FUIORESCU, D., NUTU, C., MIRICA, I., Experimental aspects of hydrogen use at diesel engine by diesel gas method, Thermal Science, First Issue 00, 2017, p. 138 15. DEB, M., SASTRY, G.R.K., BOSE, P.K, BANERJEE, R., International J ournal of Hydrogen Energy, 40, 2015, p. 8586

Manuscript received: 4.06 .2018 